\title{
Chronic obstructive pulmonary disease prevalence and prediction in a high-risk lung cancer screening population
}

John R. Goffin ${ }^{1 *} \mathbb{D}$, Gregory R. Pond ${ }^{1}$, Serge Puksa ${ }^{1}$, Alain Tremblay ${ }^{2}$, Michael Johnston ${ }^{3}$, Glen Goss ${ }^{4}$, Garth Nicholas ${ }^{4}$, Simon Martel ${ }^{5}$, Rick Bhatia ${ }^{6}$, Geoffrey Liu', Heidi Schmidt ${ }^{7}$, Sukhinder Atkar-Khattra ${ }^{8}$, Annette McWilliams ${ }^{9}$, Ming-Sound Tsao ${ }^{7}$, Martin C. Tammemagi ${ }^{10}$ and Stephen Lam $^{8}$

\begin{abstract}
Background: Chronic obstructive pulmonary disease (COPD) is an underdiagnosed condition sharing risk factors with lung cancer. Lung cancer screening may provide an opportunity to improve COPD diagnosis. Using PanCanadian Early Detection of Lung Cancer (PanCan) study data, the present study sought to determine the following: 1) What is the prevalence of COPD in a lung cancer screening population? 2) Can a model based on clinical and screening low-dose CT scan data predict the likelihood of COPD?

Methods: The single arm PanCan study recruited current or former smokers age 50-75 who had a calculated risk of lung cancer of at least $2 \%$ over 6 years. A baseline health questionnaire, spirometry, and low-dose CT scan were performed. CT scans were assessed by a radiologist for extent and distribution of emphysema. With spirometry as the gold standard, logistic regression was used to assess factors associated with COPD.

Results: Among 2514 recruited subjects, 1136 (45.2\%) met spirometry criteria for COPD, including 833 of 1987 (41.9\%) of those with no prior diagnosis, $53.8 \%$ of whom had moderate or worse disease. In a multivariate model, age, current smoking status, number of pack-years, presence of dyspnea, wheeze, participation in a high-risk occupation, and emphysema extent on LDCT were all statistically associated with COPD, while the overall model had poor discrimination ( $\mathrm{c}$-statistic $=0.627$ ( $95 \% \mathrm{Cl}$ of 0.607 to 0.650 ). The lowest and the highest risk decile in the model predicted COPD risk of 27.4 and $65.3 \%$.
\end{abstract}

Conclusions: COPD had a high prevalence in a lung cancer screening population. While a risk model had poor discrimination, all deciles of risk had a high prevalence of COPD, and spirometry could be considered as an additional test in lung cancer screening programs.

Trial registration: (Clinical Trial Registration: ClinicalTrials.gov, number NCT00751660, registered September 12, 2008)

Keywords: Lung cancer, Screening, Chronic obstructive pulmonary disease, Spirometry, CT scan

\footnotetext{
* Correspondence: goffin@mcmaster.ca

Notation of prior presentation: Presented in part at the $18^{\text {th }}$ World

Conference on Lung Cancer, October 18, 2017, Yokohama, Japan.

'Department of Oncology, McMaster University, Juravinski Cancer Centre, 699

Concession St., Hamilton, ON L8V 5C2, Canada

Full list of author information is available at the end of the article
}

(c) The Author(s). 2020 Open Access This article is licensed under a Creative Commons Attribution 4.0 International License, which permits use, sharing, adaptation, distribution and reproduction in any medium or format, as long as you give appropriate credit to the original author(s) and the source, provide a link to the Creative Commons licence, and indicate if changes were made. The images or other third party material in this article are included in the article's Creative Commons licence, unless indicated otherwise in a credit line to the material. If material is not included in the article's Creative Commons licence and your intended use is not permitted by statutory regulation or exceeds the permitted use, you will need to obtain permission directly from the copyright holder. To view a copy of this licence, visit http://creativecommons.org/licenses/by/4.0/ The Creative Commons Public Domain Dedication waiver (http://creativecommons.org/publicdomain/zero/1.0/) applies to the data made available in this article, unless otherwise stated in a credit line to the data. 


\section{Background}

Chronic obstructive pulmonary disease (COPD) and lung cancer are associated diseases, sharing tobacco as a common cause. Individuals with COPD are two times more likely to develop lung cancer than those without COPD, and individuals with emphysema on CT scan are also at higher risk [1-3]. A common pathophysiology may in part be founded on genetic susceptibility, as exemplified by two single nucleotide polymorphisms in the $\alpha$-nicotinic acetylcholine receptor (CHRNA 3/5) locus [4], but also more broadly through commonalities in oxidative stress, chronic inflammation, and changes in matrix proteinases $[5,6]$. While there are global variations in prevalence, up to one in four North Americans may be diagnosed with COPD in their lifetime $[7,8]$. Despite this, there is strong evidence of underdiagnosis of COPD in the primary care population $[9,10]$ as well as in patients who have lung cancer $[11,12]$.

Screening of asymptomatic individuals for COPD is not currently recommended by the US Preventative Services Task Force as clinical benefit has not been demonstrated in this population [13]. Conversely, based largely on the results of the National Lung Screening Trial, lowdose computed tomography (LDCT) screening for lung cancer is recommended by the US Preventative Services Task Force and funded by the Centers for Medicare and Medicaid [14-16]. Further momentum to implement screening is provided by the mortality reduction seen in the recently published, large, randomized, NELSON screening trial [17]. A significant proportion of ever smokers is found to have pulmonary emphysema on their screening low-dose CT scan (LDCT), although CT scanning alone is not sufficient to make a diagnosis of COPD [18]. While there is no disease-modifying treatment for smoking-induced COPD, treatment of individuals with moderate or worse COPD with long-acting bronchodilators with or without inhaled corticosteroids has been shown to improve lung function, improve quality of life, and decrease disease exacerbations [19].

COPD is frequently underdiagnosed in the general population [20]. Notably, the incidence of COPD exacerbation-like events has been found to be increased in both diagnosed and undiagnosed groups and health service use for exacerbation events was similarly increased in both groups [20]. Furthermore, in the NHANES III study, although undiagnosed COPD subjects appear healthier than those with a diagnosis, their risk of death was increased compared with subjects without obstruction and that the risk of death may be influenced by lung function [21]. The prevalence of undiagnosed or under-reported COPD in a lung cancer screening population when a risk prediction model such as the PLCOm2012 that incorporates questions on a personal history of COPD is used to assess lung cancer risk is not known [22, 23]. We analyzed the Pan-Canadian Early Detection of Lung Cancer (PanCan) Study data to evaluate the frequency of diagnosed and undiagnosed COPD in a population undergoing lung cancer screening using the PanCan prediction model, a precursor to the PLCOm2012 model, to assess whether spirometry should be routinely performed in lung cancer screening [24].

\section{Methods}

The PanCan study was a single arm lung cancer screening study which recruited from September, 2008, to December, 2010, in 8 Canadian centers. The study was approved at McMaster University by the Hamilton Integrated Research Ethics Board (project 08-367) and by the local ethics board at each study site. Candidates were screened for eligibility using the PanCan model, a prototype of the PLCOm2012 model, which included age (50-75 required), sex, smoking history, family history of lung cancer, personal history of chronic obstructive pulmonary disease, chest X-ray within 3 years, education level, and body-mass index, with the requirement for a 6 -year risk of lung cancer $\geq 2 \%[24,25]$. Candidates were excluded for significant pre-existing cardiopulmonary conditions, prior lung cancer, other recent cancers, smoking cessation for greater than 15 years, pregnancy, or CT scan within 2 years. Consenting and eligible subjects undertook a detailed health and high-risk occupational exposure questionnaire (listed in Additional file 1: e-Appendix 1), spirometry, and LDCT of the chest. The study included autofluorescence bronchoscopy and blood biomarkers, which are not evaluated here [26]. The study achieved a $6.5 \%$ cancer incidence over a median 5.5 years of follow-up [24].

Spirometry was undertaken according to American Thoracic Society recommendations with central quality assurance of spirometry tracings [27]. COPD was defined as "definite" with a forced expiratory volume (first second) $\left(\mathrm{FEV}_{1}\right)$ to forced vital capacity (FVC) ratio of $<0.7$ post-bronchodilator. COPD was defined as "probable" with a pre-bronchodilator $\mathrm{FEV}_{1} / \mathrm{FVC}<0.7$ if no post-bronchodilator value was available and there was no prior diagnosis of asthma, or "uncertain" with a pre-bronchodilator $\mathrm{FEV}_{1} / \mathrm{FVC}<0.7$ if no postbronchodilator value was available and there was a prior diagnosis of asthma.

LDCT was conducted with minimum section collimation of $1.25 \mathrm{~mm}$, at least 4 data acquisition channels, at $120 \mathrm{kV}, 40-50 \mathrm{~mA}$, beam pitch 1.5 to achieve an effective dose of $<2 \mathrm{mSv}$. Lung parenchyma was reconstructed with a high spatial frequency algorithm and an intermediate spatial frequency algorithm was used for mediastinal structures.

The radiologists' visual assessment of the extent of emphysema was recorded on a five-point scale (none, minimal, mild, moderate, and severe) and spatial 
distribution was recorded using a four-point scale (upper, mid, lower, or diffuse) [28].

\section{Statistics}

The primary outcome was a diagnosis (definite, probable, uncertain or no evidence) of COPD based on spirometry. Patients were classified as having of COPD if they had definite or probable COPD. Amongst these patients, severity of COPD was graded using the Global Initiative for Chronic Obstructive Lung Disease (GOLD) criteria.

Summary statistics were used to describe subject characteristics for the population as a whole, and by whether they self-reported a prior diagnosis of COPD. The $x^{2}$ test and Wilcoxon rank sum test were used to compare the self-reported diagnosis of COPD with patient characteristics, symptoms, prior imaging frequency and radiologist diagnosis of COPD. Logistic regression analyses were used to evaluate prognostic ability of factors on COPD diagnosis as defined by spirometry. Backward selection was used to construct a recommended multivariable model of factors. Residual plots were inspected to assess for non-linear associations and goodness of fit. Discrimination ability was assessed using the concordance statistic. The model was assessed for clinical utility by calculating the risk score as determined by the recommended multivariable model and comparing the risk score with actual risk of COPD. For ease of interpretation, patients were categorized by risk score into deciles. Bootstrapping was then performed to evaluate internal validity of the model based on 2000 bootstrap samples. All estimates and tests were two-sided and statistical significance was defined as a $p$-value $\leq 0.05$.

\section{Results}

Among 2537 subjects recruited to the PanCan study, 2514 had available spirometry data and were included in the analysis. Of these, 527 self-reported a prior diagnosis of COPD and 1987 did not (Table 1). Those reporting a prior diagnosis of COPD were more likely to be female (52 vs $42.7 \%$ ), were less likely to have completed a secondary school education (14.5 vs $22.2 \%$ ) or completed post-secondary education (41.6 vs $48.6 \%$ ), and had a

Table 1 Population Characteristics by Prior COPD Diagnosis

\begin{tabular}{|c|c|c|c|c|}
\hline Characteristic & $\begin{array}{l}\text { Overall Population }(N= \\
\text { 2514) }\end{array}$ & $\begin{array}{l}\text { Prior Diagnosis COPD }(N= \\
\text { 527) }\end{array}$ & $\begin{array}{l}\text { No Prior Diagnosis COPD }(N= \\
1987)\end{array}$ & $\begin{array}{l}p- \\
\text { value }^{*}\end{array}$ \\
\hline Age, mean (std dev) & $62.3(5.8)$ & $62.1(6.1)$ & $62.4(5.8)$ & 0.38 \\
\hline Gender, male, N (\%) & $1391(55.3)$ & $253(48.0)$ & $1138(57.3)$ & $<0.001$ \\
\hline Education $<$ secondary & $405(16.1)$ & $117(22.2)$ & $288(14.5)$ & $<0.001$ \\
\hline -secondary school & $924(36.8)$ & $191(36.3)$ & $733(36.9)$ & \\
\hline -post-secondary & $1185(47.1)$ & $219(41.6)$ & $966(48.6)$ & \\
\hline Pack Years, mean (range) & $50(2.2,230)$ & $52.5(2.4,230)$ & $50(2.2,169)$ & $<0.001$ \\
\hline Lung Cancer Risk mean (range) & $3.4(2.0,38.2)$ & $4.4(2.0,34.4)$ & $3.2(2.0,38.2)$ & $<0.001$ \\
\hline Current Smoker, n (\%) & $1566(62.3)$ & $305(57.9)$ & $1261(63.5)$ & 0.020 \\
\hline Dyspnea, n (\%) & $1133(45.1)$ & $394(74.8)$ & $739(37.2)$ & $<0.001$ \\
\hline Cough, n (\%) & $1316(52.4)$ & $361(68.5)$ & $955(48.1)$ & $<0.001$ \\
\hline Phlegm, n (\%) & $1161(46.2)$ & $329(62.4)$ & $832(41.9)$ & $<0.001$ \\
\hline Wheeze, n (\%) & $943(37.5)$ & $316(60.0)$ & $627(31.6)$ & $<0.001$ \\
\hline $\begin{array}{l}\text { Any High Risk Occupation, n } \\
(\%)\end{array}$ & $884(35.2)$ & $198(37.6)$ & $686(34.5)$ & 0.20 \\
\hline CXR within 3 years $=0$ & $1017(40.5)$ & $121(23.0)$ & $896(45.1)$ & $<0.001$ \\
\hline$=1$ & $891(35.4)$ & $212(40.2)$ & $679(34.2)$ & \\
\hline$\geq 2$ & $606(24.1)$ & $194(36.8)$ & $412(20.7)$ & \\
\hline$C T$ within 3 years $=0$ & $2441(97.1)$ & $512(97.2)$ & $1929(97.1)$ & 0.86 \\
\hline$=1$ & $68(2.7)$ & $13(2.5)$ & $55(2.8)$ & \\
\hline$=2$ & $5(0.2)$ & $2(0.4)$ & $3(0.2)$ & \\
\hline Asthma, n (\%) & $244(9.7)$ & $117(22.2)$ & $127(6.4)$ & $<0.001$ \\
\hline Pulmonary Fibrosis, n (\%) & $3(0.1)$ & $1(0.2)$ & $2(0.1)$ & 0.51 \\
\hline Pneumonia, n (\%) & $672(26.7)$ & $225(42.7)$ & $447(22.5)$ & $<0.001$ \\
\hline Respiratory Failure, n (\%) & $11(0.4)$ & $8(1.5)$ & $3(0.2)$ & $<0.001$ \\
\hline
\end{tabular}

*Comparison of prior diagnosis of COPD to no prior diagnosis of COPD by chi-square (categorical variables) and Wilcoxon rank sum test (continuous) 
higher mean pack-year smoking history ( 52.5 vs. 50 years) (all $p<0.001$ ). A reported prior COPD diagnosis also conferred a higher likelihood of reporting symptoms of dyspnea, cough, phlegm, or wheeze, a greater likelihood of having one or more chest X-rays in the last 3 years (77 vs $54.9 \%$ ), and a more common history of other respiratory disease (asthma, pneumonia, respiratory failure) (all $p<0.001$ ).

In the overall population, spirometry defined COPD was found in 1136 individuals (45.2\%), including 833 (41.9\%) of those with no prior diagnosis of COPD (Table 2). Among those who did not report a prior diagnosis of COPD, $53.8 \%$ of new, spirometry-based COPD diagnoses were classified as moderate or worse severity according to GOLD criteria. Conversely, among those who reported a prior diagnosis of COPD, 32.2\% did not meet spirometry criteria for COPD.

The relationship between COPD diagnosed by spirometry and emphysema severity reported by LDCT was poor (Weighted Kappa =0.16) (Fig. 1). Among 1378 individuals having no COPD by spirometry, 361 (26.2\%) had mild or worse emphysema by LDCT report. By contrast, among 97 individuals with severe or very severe disease by spirometry, $38(39.2 \%)$ had no or trivial COPD by LDCT report.

Table 3 shows the factors associated with a prior selfreported COPD diagnosis (irrespective of spirometry diagnosis). In the multivariable model, symptoms of dyspnea, wheeze, cough and phlegm, number of comorbidities, and being an ex-smoker were all associated with having a prior diagnosis of COPD. Female sex, a lower average education level, greater pack-year smoking history, and chest $\mathrm{x}$-ray testing were associated with COPD only on univariable analysis.

In assessing factors associated with COPD by spirometry criteria, following backward selection, the final multivariable model included age, current smoking status, number of pack-years, presence of dyspnea, wheeze, participation in a high-risk occupation, and emphysema extent on LDCT (Table 4). The c-statistic, which is a measure of discriminatory ability, was 0.627 (95\% CI $=$ 0.607 to 0.650 ), which is generally considered poor discrimination.

Despite their association with a prior diagnosis of COPD and prediction of a spirometry-based diagnosis of COPD, only $51.1 \%(579 / 1133)$ of patients with dyspnea and $50.7 \%$ (478/943) with wheeze met the GOLD criteria for diagnosis, while $37.7 \%$ (245/650) of subjects having no respiratory symptom also met the criteria for COPD. Similarly, $47.3 \%$ (740/1566) of current smokers met GOLD criteria for COPD, as did $41.8 \%(396 / 948)$ of former smokers.

Table 5 shows the actual risk of COPD based on model predicted risk deciles. Those in the lowest predicted risk decile still had an actual observed rate of COPD of $27.4 \%$. There is a gradual increase in the rate of COPD by decile to a rate of $75.0 \%$ in the highest risk decile. Calibration is assessed by how closely the predicted estimate is with the observed estimate. In two of the ten deciles, the predicted estimate falls outside the range of the $95 \%$ bias-corrected and accelerated (BCa) confidence intervals, which is calculated via bootstrapping.

\section{Discussion}

With data now supporting LDCT screening for lung cancer, a large population of tobacco users may now have contact with screening programs [14]. This offers the opportunity to consider a wider use of such programs to improve the health of this population. The most obvious add-on to such programs has been tobacco cessation. The lung cancer screening population, including those ineligible for trials, express interest in smoking cessation $[29,30]$. Smoking cessation interventions are

Table 2 Table of Prior Known COPD status vs. Spirometry COPD Diagnosis

\begin{tabular}{|c|c|c|c|c|}
\hline Characteristic & $\begin{array}{l}\text { Overall Population } \\
(N=2514)\end{array}$ & $\begin{array}{l}\text { Prior Diagnosis of COPD } \\
(N=527) \\
\mathrm{n}(\%)\end{array}$ & $\begin{array}{l}\text { No prior diagnosis of COPD } \\
(N=1987) \\
\mathrm{n}(\%)\end{array}$ & $p$-value* \\
\hline COPD by Spirometry: & & & & $<0.001$ \\
\hline Definite/Probable & $1136(45.2)$ & $303(57.5)$ & $833(41.9)$ & \\
\hline Uncertain & $107(4.3)$ & $54(10.3)$ & $53(2.7)$ & \\
\hline None & $1271(50.6)$ & $170(32.2)$ & $1101(55.4)$ & \\
\hline $\begin{array}{l}\text { Severity of Spirometry Diagnosis COPD } \\
\text { (among definite/probable) }\end{array}$ & & & & $<0.001$ \\
\hline Stage I (Mild) & $456(40.1)$ & $71(23.4)$ & $385(46.2)$ & \\
\hline Stage II (Moderate) & $583(51.3)$ & $173(57.1)$ & $410(49.2)$ & \\
\hline Stage III (Severe) & $87(7.7)$ & $51(16.8)$ & $36(4.3)$ & \\
\hline Stage IV (Very Severe) & $10(0.9)$ & $8(2.6)$ & $2(0.2)$ & \\
\hline
\end{tabular}

*Comparison of prior diagnosis of COPD to no prior diagnosis of COPD by chi-square 


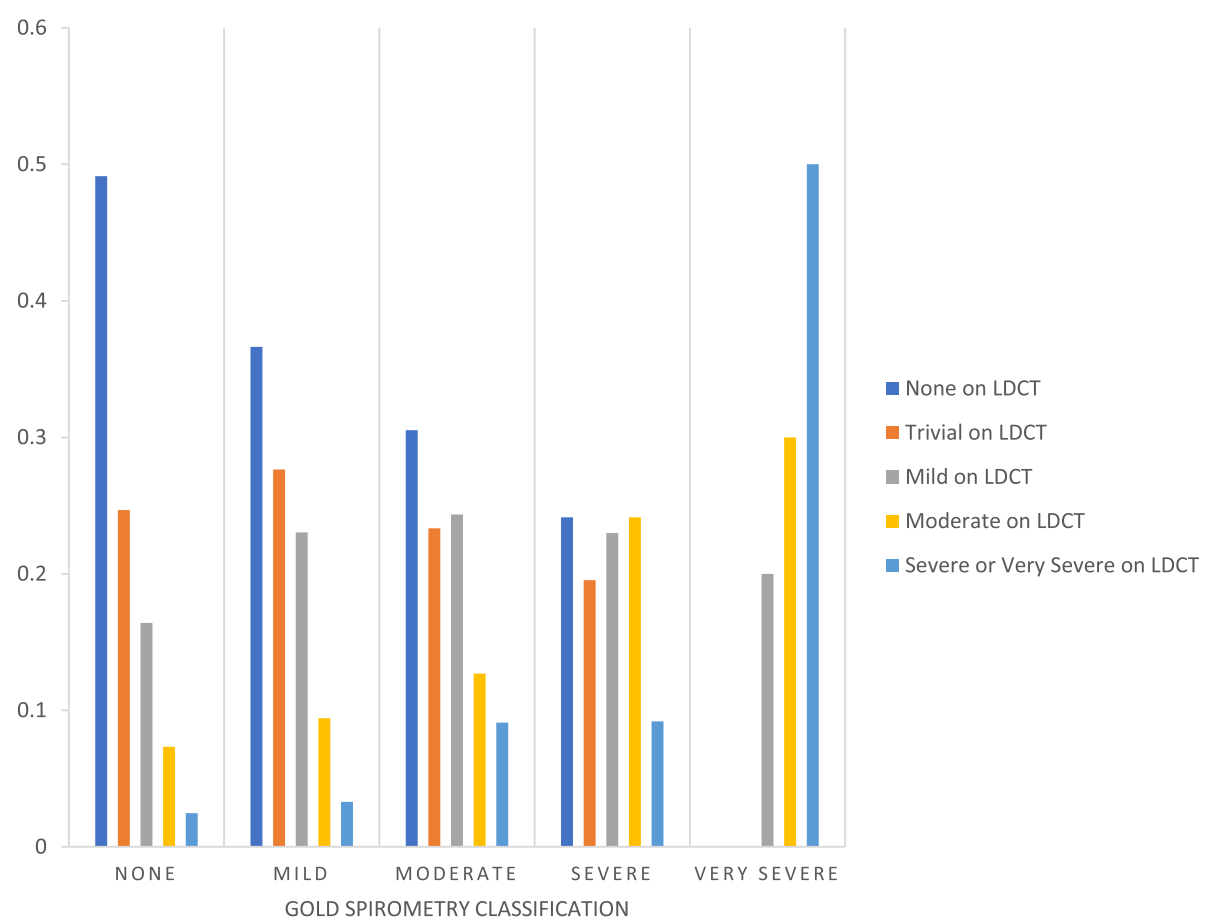

Fig. 1 COPD severity as determined by low-dose CT according to GOLD classification by spirometry. Footnote to figure: -Due to small numbers, low-dose CT (LDCT) groupings of severe $(n=97)$ and very severe $(n=18)$ COPD were combined. -Weighted Kappa $=0.16$

highly cost effective [31] and provide survival benefits likely to exceed the benefit of screening itself [32].

The present work suggests that the lung cancer screening population would also benefit from concurrent screening for COPD by spirometry. The association between COPD and lung cancer has already been demonstrated [1, 2]. COPD is a factor in modeling risk for lung cancer [23], and COPD has also been shown to have a higher prevalence in a lung cancer population [33]. At the end of life, individuals with COPD have care needs comparable to individuals with lung cancer [34, 35], and COPD confers a significant economic burden [36, 37]. Appropriate management of individuals with COPD is likely to improve quality of life at a reasonable cost [38-41].

In the PanCan study, the prevalence of COPD was $45.2 \%$ as defined by spirometry. This is slightly higher than that observed in the ACRIN population of the $\mathrm{Na}$ tional Lung Screening Trial (34.4\%) and the NELSON screening study $(38.3 \%)[18,42]$. While the difference is not readily explained by the relative age and smoking history of the cohorts, a prior history of COPD was used in the risk model of the PanCan study. In the PanCan population without a prior diagnosis of COPD, $41.9 \%$ met criteria by spirometry. Among those diagnosed with COPD, 59.9\% had moderate or worse disease.

Conversely, $32.2 \%$ of subjects reporting a diagnosis of COPD did not meet spirometry criteria for a COPD diagnosis. Although we do not know what portion of these individuals previously had spirometry, FernandezVillar et al. found that $21.6 \%$ of those undergoing spirometry were incorrectly diagnosed as having COPD despite showing a non-obstructive pattern [43]. In our study, individuals with self-reported COPD more commonly reported respiratory symptoms, symptoms which might have served as diagnostic triggers for clinicians. The fact that such individuals were also more likely to be ex-smokers raises the question of whether their symptoms, reported COPD diagnosis, or resulting medical care motivated tobacco cessation. While by GOLD definition these patients were misdiagnosed, emerging data suggests that half of current and former smokers not meeting spirometry criteria may suffer respiratory symptoms, with an increase in respiratory exacerbations and a loss quality of life $[44,45]$. It is presently unclear how to address the needs of this population.

CT changes of emphysema were reported in just over half of individuals (50.9\%) not having COPD according to spirometry. Previous investigators have found that a portion of individuals diagnosed with COPD by $\mathrm{CT}$ do not meet criteria by spirometry $[46,47]$. In a large population with respiratory symptoms not meeting spirometry criteria, Regan et al. found that $42.3 \%$ had CT evidence of either emphysema (24.0\%) or airway thickening (30.7\%) [44]. The reason for this apparent mismatch between radiologic and spirometric findings is not clear. Given that other studies have made similar findings, 
Table 3 Factors Associated with a Prior Diagnosis of COPD

\begin{tabular}{|c|c|c|}
\hline Characteristic & Odds Ratio $(95 \% \mathrm{Cl})$ & $p$-value \\
\hline \multicolumn{3}{|l|}{ UNIVARIABLE MODEL } \\
\hline Age / year & $0.99(0.98,1.01)$ & 0.29 \\
\hline Sex Male vs Female & $0.69(0.57,0.84)$ & $<0.001$ \\
\hline Education Level / unit & $0.89(0.84,0.94)$ & $<0.001$ \\
\hline Age Started Smoking / year & $0.98(0.95,1.01)$ & 0.24 \\
\hline Average Cigarettes / Day Smoked (Log-transformed) & $1.94(1.53,2.47)$ & $<0.001$ \\
\hline Pack Years (Log-transformed) & $1.81(1.43,2.29)$ & $<0.001$ \\
\hline Presently a Smoker Yes vs No & $0.79(0.65,0.96)$ & 0.019 \\
\hline Serious Attempt to Quit (of those who are presently a smoker) Yes vs No & $1.09(0.74,1.62)$ & 0.66 \\
\hline $\begin{array}{l}\text { \# of Healthcare Professionals Asking About Smoking (of those who } \\
\text { are presently a smoker) / time }\end{array}$ & $1.90(1.41,2.56)$ & $<0.001$ \\
\hline Dyspnea Yes vs No & $5.00(4.03,6.21)$ & $<0.001$ \\
\hline Cough Yes vs No & $2.35(1.92,2.88)$ & $<0.001$ \\
\hline Phlegm Yes vs No & $2.31(1.89,2.81)$ & $<0.001$ \\
\hline Wheeze Yes vs No & $3.25(2.66,3.96)$ & $<0.001$ \\
\hline Any High Risk Occupation Yes vs No & $1.14(0.94,1.39)$ & 0.19 \\
\hline Chest $X$-Rays $\geq 1$ vs 0 & $2.76(2.21,3.44)$ & $<0.001$ \\
\hline CT Scans $\geq 1$ vs 0 & $0.98(0.55,1.73)$ & 0.93 \\
\hline Number of Comorbidities $\geq 1$ vs 0 & $2.57(2.04,3.25)$ & $<0.001$ \\
\hline \multicolumn{3}{|l|}{ MULTIVARIABLE MODEL } \\
\hline Dyspnea Yes vs No & $3.38(2.67,4.27)$ & $<0.001$ \\
\hline Wheeze Yes vs No & $1.86(1.48,2.35)$ & $<0.001$ \\
\hline Cough Yes vs No & $1.47(1.13,1.91)$ & 0.004 \\
\hline Phlegm Yes vs No & $1.35(1.05,1.74)$ & 0.019 \\
\hline Number of Comorbidities $\geq 1$ vs 0 & $1.98(1.54,2.56)$ & $<0.001$ \\
\hline Presently a Smoker Yes vs No & $0.53(0.42,0.66)$ & $<0.001$ \\
\hline
\end{tabular}

-Comorbidities include coronary artery disease, angina, myocardial infarction, congestive heart failure, peripheral vascular disease, asthma, pneumonia, respiratory failure, and any cancer

-Education was collected on a 7 level/unit scale, but grouped in Table 1 according to secondary and post-secondary completion

there is likely a population for whom the changes observed on CT are physiologically insufficient to make a formal diagnosis of COPD possible. This is consistent with data which suggests that early radiologic changes presage later changes in spirometry [48]. Certainly, the extent to which CT changes are detected in individuals without COPD by spirometry will depend on which CT changes are sought, as exemplified by the work of Regan et al. [44].

In our population, the relationship between severity of COPD by LDCT as compared to $\mathrm{FEV}_{1}$ was poor, although LDCT did contribute to COPD prediction in our model. By comparison, in another low-dose CT screening population, Omori et al. found a modest association between a visual, semi-quantitative emphysema score and spirometry findings [47]. While data from the COPDGene study showed that subjective readings of emphysema in standard dose CT imaging correlated well with quantitative results and spirometry [49], other data suggests radiologists are more likely to overestimate COPD than would a CT densitometry algorithm [28].

To improve sensitivity for emphysema, investigators in Japan added a single-slice high resolution CT of the upper lung field to a low-dose CT scan screening program for lung cancer. Of note, 100 (16\%) of 615 subjects were never smokers. Using visual classification, investigators increased the detection of low attenuation from 6.4\% with LDCT alone to $23.3 \%$ with a HRCT slice [50].

Mets et al. published a large $(n=1140)$ single centre analysis of patients from the NELSON trial [18]. CT diagnosis of emphysema was based on percentage of lung attenuation below - 950 Hounsfield units and air trapping was assessed with expiratory CT views. A model incorporating the $\mathrm{CT}$ factors plus body mass index, pack-years of smoking, and current smoking status had a ROC curve AUC of 0.83 (95\% CI, 0.81-0.86), 
Table 4 Predictive factors of COPD defined by spirometry

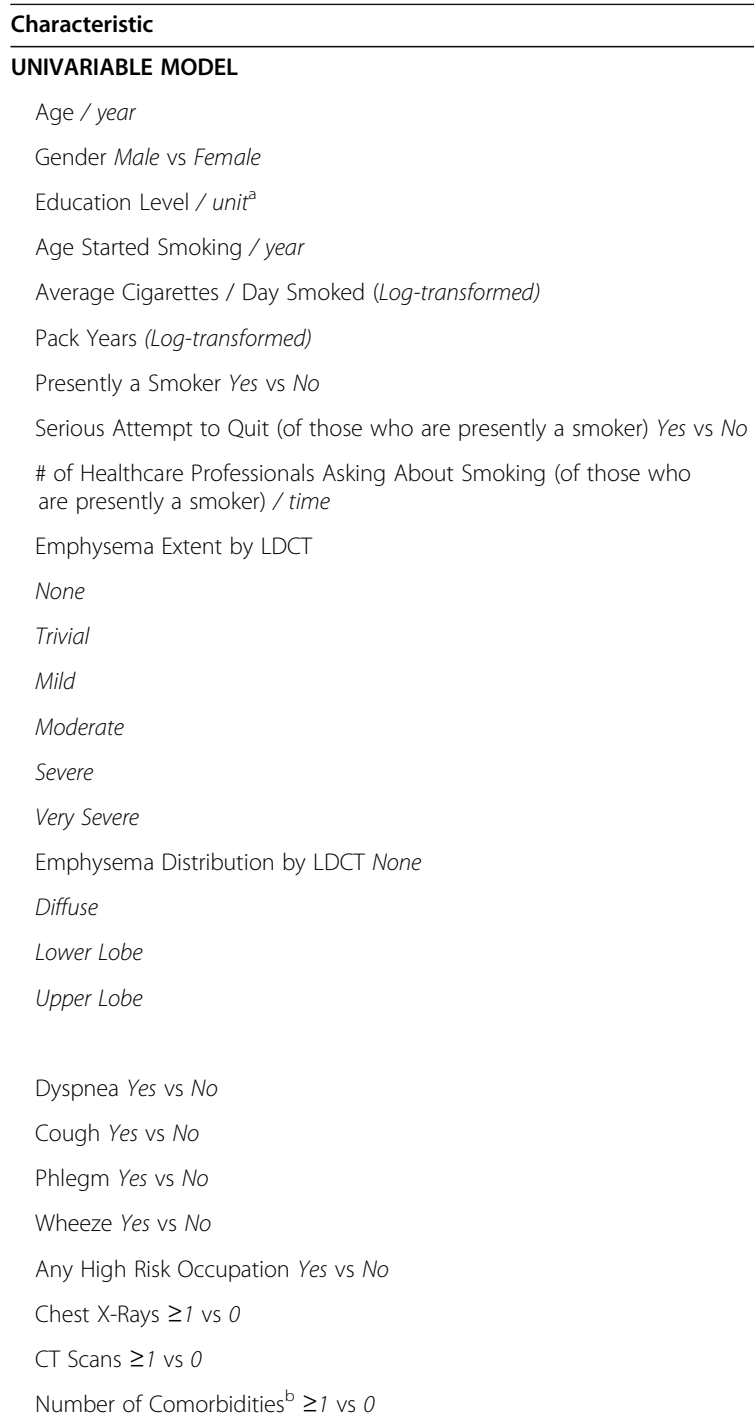

\section{NIVARIABLE MODEL}

Gender Male vs Female

Level / unit

Smoked (Log-transformed)

Pack Years (Log-transformed)

Serious Attempt to Quit (of those who are presently a smoker) Yes vs No

\# of Healthcare Professionals Asking About Smoking (of those who

None

Trivial

Moderate

Severe

Very Severe

Emphysema Distribution by LDCT Non

Diffuse

Lower Lobe

Number of Comorbidities ${ }^{b} \geq 1$ vs 0

\section{Odds Ratio $(95 \% \mathrm{Cl})$}

$p$-value

MULTIVARIABLE MODEL

Emphysema Extent

None

Trivial

Mild

Moderate

Severe

Very Severe

Age / year

Dyspnea Yes vs No

Presently a Smoker Yes vs No

Pack Years (Log-transformed)

Wheeze Yes vs No

Any High Risk Occupation Yes vs No
$1.05(1.03,1.06)$

$<0.001$

$1.39(1.19,1.63)$

$0.97(0.92,1.01)$

$1.01(0.98,1.03)$

$1.24(1.03,1.49)$

$1.49(1.24,1.79)$

$1.25(1.06,1.47)$

$1.19(0.88,1.61)$

$0.85(0.69,1.06)$

Reference

$<0.001$

$1.52(1.24,1.86)$

$2.20(1.77,2.74)$

$2.58(1.94,3.44)$

$3.76(2.42,5.85)$

$14.76(3.38,64.47)$

Reference

$<0.001$

$1.60(1.24,2.06)$

$1.68(0.73,3.83)$

$2.19(1.84,2.60)$

$1.55(1.32,1.81)$

$1.23(1.05,1.44)$

$<0.001$

$1.19(1.02,1.40)$

0.010

0.028

$1.43(1.21,1.68)$

$<0.001$

$1.25(1.06,1.47)$

0.008

$1.24(1.05,1.45)$

0.010

$1.99(1.23,3.21)$

0.005

$1.03(0.83,1.28)$
Reference

$1.51(1.23,1.86)$

$2.05(1.64,2.57)$

$2.37(1.77,3.18)$

$3.09(1.97,4.86)$

$10.66(2.40,47.37)$

$1.06(1.04,1.07)$

$<0.001$

$1.33(1.11,1.59)$

0.002

$1.38(1.15,1.65)$

$<0.001$

$1.34(1.10,1.63)$

0.003

$1.25(1.04,1.51)$

0.020

$1.21(1.02,1.44)$

${ }^{a}$ Education was collected on a 7 level/unit scale, but grouped in Table 1 according to secondary and post-secondary completion

${ }^{b}$ Comorbidities include coronary artery disease, angina, myocardial infarction, congestive heart failure, peripheral vascular disease, asthma, pneumonia, respiratory failure, and any cancer 
Table 5 Actual COPD risk by model risk decile

\begin{tabular}{lllll}
\hline Decile & Predicted Estimate & N & N (\%) with COPD & 95\% BCa Bootstrap CI \\
\hline 1 & $27.8 \%$ & 252 & $69(27.4)$ & $21.4-35.5$ \\
2 & $33.7 \%$ & 251 & $77(30.7)$ & $24.7-36.7$ \\
3 & $37.4 \%$ & 251 & $83(33.1)$ & $26.7-38.7$ \\
4 & $40.4 \%$ & 251 & $80(31.9)$ & $25.9-37.2$ \\
5 & $43.4 \%$ & 252 & $108(42.9)$ & $36.1-48.8$ \\
6 & $46.3 \%$ & 251 & $117(46.6)$ & $40.2-52.5$ \\
7 & $49.5 \%$ & 251 & $127(50.6)$ & $43.8-56.2$ \\
8 & $53.0 \%$ & 252 & $143(56.8)$ & $51.2-62.7$ \\
9 & $57.5 \%$ & 251 & $143(57.0)$ & $50.6-62.2$ \\
10 & $65.3 \%$ & 252 & $189(75.0)$ & $69.4-80.2$ \\
\hline
\end{tabular}

with sensitivity of $63 \%$ and a specificity of $88 \%$ to detect COPD as compared with pre-bronchodilator spirometry.

Our study was conducted using LDCT without additional CT maneuvers in a population at higher risk for lung cancer (smoking history median 50 vs. 38 packyears), a scenario more likely to be adopted by jurisdictions with resource constraints. In this context, our COPD prediction model had poor discrimination.

Importantly, when we assess the PanCan population by COPD risk estimate decile, even the lowest decile still had an estimated risk for COPD of $27.8 \%$, with the top decile having a risk of $65.3 \%$. In light of the limited sensitivity of our and others' risk models, the COPD risk in our population is arguably sufficient to warrant spirometry testing of all screened patients, regardless of number of risk factors. Our data show that the use of symptoms or current smoking status without spirometry will frequently lead to an incorrect diagnosis of COPD.

This exploratory analysis of a prospective trial has limitations. Prior diagnosis of COPD was based on patient recall, and reported symptoms and history were only captured at baseline; any associations between the two are therefore hypothesis generating. Post-bronchodilator spirometry values were not used in all cases, requiring us to define a group with 'probable' COPD. LDCT reading was conducted by experienced and study-trained radiologists, but software analysis was not employed, and interpretation is necessarily subjective. The use of imaging software may enhance COPD diagnosis and could be more cost-effective than additional CT maneuvers. The PanCan cohort was comparatively high risk for lung cancer, and our findings of COPD prevalence may not extrapolate to lower risk screening populations.

\section{Conclusions}

The primary goal of LDCT screening has been to diminish the risk of death from lung cancer. It has been recognized that screening also provides an opportunity for a smoking cessation intervention. The present study demonstrates that being eligible for high-risk lung cancer screening confers a substantial risk of having underlying COPD. While the presence of clinical factors and emphysema on LDCT are somewhat predictive of COPD, no subpopulation in our study could be considered as low risk. For those conducting LDCT screening for lung cancer in a high-risk population, consideration should be given to universal spirometric assessment for COPD.

\section{Supplementary Information}

The online version contains supplementary material available at https://doi. org/10.1186/s12890-020-01344-y.

\section{Additional file 1.}

Additional file 2

\section{Abbreviations}

COPD: Chronic obstructive pulmonary disease; FEV1: Forced expiratory volume (first second); FVC: Forced vital capacity; GOLD: Global Initiative for Chronic Obstructive Lung Disease; LDCT: Low-dose CT scan

\section{Acknowledgements}

Not applicable.

\section{Authors' contributions}

JRG conceived the manuscript. GRP performed statistical analysis. The manuscript was drafted by JRG and GRP and revised critically and approved by SP, AT, MJ, GG, GN, SM, RB, GL, HS, SAK, AM, MST, and SL. JRG, SP, AT, MJ, $\mathrm{GG}, \mathrm{GN}, \mathrm{SM}, \mathrm{RB}, \mathrm{GL}, \mathrm{HS}, \mathrm{SAK}, \mathrm{AM}, \mathrm{MST}$, and $\mathrm{SL}$ are investigators and authors of the Pan-Canadian Early Detection of Lung Cancer study and contributed to data collection. All authors give final approval of the version to be published. All authors take responsibility for the content of the manuscript and hold themselves accountable for the accuracy and integrity of any part of the work.

\section{Funding}

The Terry Fox Research Institute and the Canadian Partnership Against Cancer provided funding but had no role in study design or collection, analysis or interpretation, nor in writing of the manuscript.

Availability of data and materials

The dataset analysed during the current study are available from the corresponding author on reasonable request. 


\section{Ethics approval and consent to participate}

The study was approved by the research ethics boards at each of the 8 recruitment sites, as listed in Additional file 2. All subjects signed informed consent.

\section{Consent for publication}

Not applicable.

\section{Competing interests}

The following authors certify that they have no conflict of interest to declare, i.e. affiliations with or involvement in any organization or entity with any financial or non-financial interest in the subject matter or materials discussed in this manuscript: RB, SK, SL, GL, MJ, S. Martel, HS, MT, GG, GN, MST. The following authors report the details of potential conflicts of interest: JRG: Honorarium from Merck (2018). Conference travel support from AstraZeneca (2017). Speaking fee from Amgen (2018). Ongoing funding from the Canadian Partnership Against Cancer; GP: family member who works for Roche Canada. Owns stock in Roche Canada. Received honorariums from Takeda and Astra-Zeneca; AT: Consultant Olympus Respiratory America. Consultant, Royalties BD Inc.; SP: GSK - speaker bureau activities. Astra-Zeneca speaker bureau activities, local advisory board member. Merck - speaker bureau activities. Boehringer - speaker bureau activities, local advisory board member.

\section{Author details}

${ }^{1}$ Department of Oncology, McMaster University, Juravinski Cancer Centre, 699 Concession St., Hamilton, ON L8V 5C2, Canada. ${ }^{2}$ University of Calgary, 3300 Hospital Drive NW, Calgary, AB T2N 4N1, Canada. ${ }^{3}$ Dalhousie University, 5850 College St, PO Box 15000, Halifax, NS B3J 3Z3, Canada. ${ }^{4}$ Ottawa Hospital Research Institute, University of Ottawa, 501 Smyth Rd, Box 511, Ottawa, ON $\mathrm{K} 1 \mathrm{H}$ 8L6, Canada. ${ }^{5}$ Centre de recherche de I'Institut universitaire de cardiologie et pneumonolgie de Québec, Université Laval, QC, Québec G1V 4G5, Canada. ${ }^{6}$ Health Sciences Centre - General Hospital, Memorial University, 300 Prince Phillip Dr, St. John's, NF A1B 3V6, Canada. University Health Network and Princess Margaret Cancer Centre, 610 University Ave, Toronto, ON M5G 2M9, Canada. ${ }^{8}$ British Columbia Cancer Research Centre, University of British Columbia, 675 West 10th Ave, Vancouver, BC V5Z 1L3, Canada. ${ }^{9}$ Fiona Stanley Hospital, University of Western Australia, 11 Robin Warren Dr, Murdoch, W Australia 6150, Australia. ${ }^{10}$ Department of Health Sciences, Brock University, Walker Complex South, Rm 306, 500 Glenridge Ave, St. Catharines, ON L2S 3A1, Canada.

Received: 13 August 2020 Accepted: 9 November 2020

Published online: 16 November 2020

\section{References}

1. Brenner DR, McLaughlin JR, Hung RJ. Previous lung diseases and lung cancer risk: a systematic review and meta-analysis. PLoS One. 2011;6(3): e17479

2. Koshiol J, Rotunno M, Consonni D, Pesatori AC, De Matteis S, Goldstein AM, Chaturvedi AK, Wacholder S, Landi MT, Lubin JH, et al. Chronic obstructive pulmonary disease and altered risk of lung cancer in a population-based case-control study. PLoS One. 2009;4(10):e7380.

3. de-Torres JP, Wilson DO, Sanchez-Salcedo P, Weissfeld JL, Berto J, Campo A, Alcaide AB, Garcia-Granero M, Celli BR, Zulueta JJ. Lung cancer in patients with chronic obstructive pulmonary disease. Development and validation of the COPD Lung Cancer Screening Score. Am J Respir Crit Care Med. 2015. 191(3):285-91

4. Pillai SG, Ge D, Zhu G, Kong X, Shianna KV, Need AC, Feng S, Hersh CP, Bakke P, Gulsvik A, et al. A genome-wide association study in chronic obstructive pulmonary disease (COPD): identification of two major susceptibility loci. PLoS Genet. 2009;5(3):e1000421.

5. Houghton AM. Mechanistic links between COPD and lung cancer. Nat Rev Cancer. 2013;13(4):233-45.

6. Durham AL, Adcock IM. The relationship between COPD and lung cancer. Lung Cancer. 2015;90(2):121-7.

7. Gershon AS, Warner L, Cascagnette P, Victor JC, To T. Lifetime risk of developing chronic obstructive pulmonary disease: a longitudinal population study. Lancet. 2011;378(9795):991-6.

8. Lamprecht B, Soriano JB, Studnicka M, Kaiser B, Vanfleteren LE, Gnatiuc L, Burney P, Miravitlles M, Garcia-Rio F, Akbari K, et al. Determinants of underdiagnosis of COPD in national and international surveys. Chest. 2015; 148(4):971-85.

9. Bednarek M, Maciejewski J, Wozniak M, Kuca P, Zielinski J. Prevalence, severity and underdiagnosis of COPD in the primary care setting. Thorax. 2008;63(5):402-7.

10. Hill K, Goldstein RS, Guyatt GH, Blouin M, Tan WC, Davis LL, Heels-Ansdell DM, Erak M, Bragaglia PJ, Tamari IE, et al. Prevalence and underdiagnosis of chronic obstructive pulmonary disease among patients at risk in primary care. CMAJ : Canadian Medical Association journal = journal de l'Association medicale canadienne. 2010;182(7):673-8.

11. Sekine $Y$, Katsura $H$, Koh E, Hiroshima K, Fujisawa T. Early detection of COPD is important for lung cancer surveillance. Eur Respir J. 2012;39(5):1230-40.

12. Zhang J, Zhou JB, Lin XF, Wang Q, Bai CX, Hong QY. Prevalence of undiagnosed and undertreated chronic obstructive pulmonary disease in lung cancer population. Respirology. 2013;18(2):297-302.

13. Siu AL, Bibbins-Domingo K, Grossman DC, Davidson KW, Epling JW, García FAR, Gillman M, Kemper AR, Krist AH, Kurth AE, et al. Screening for Chronic Obstructive Pulmonary Disease. Jama. 2016;315:13.

14. Aberle DR, Adams AM, Berg CD, Black WC, Clapp JD, Fagerstrom RM, Gareen IF, Gatsonis C, Marcus PM, Sicks JD. Reduced lung-cancer mortality with low-dose computed tomographic screening. N Engl J Med. 2011; 365(5):395-409.

15. Moyer VA, Force USPST. Screening for lung cancer: U.S. Preventive Services Task Force recommendation statement. Ann Intern Med. 2014;160(5):330-8.

16. Centers for Medicare \& Medicaid Services. Final national coverage determination on screening for lung cancer with Low Dose Computed Tomography (LDCT)(CAG-00439N). Baltimore; 2015. https://www.cms.gov/ medicare-coverage-database/details/nca-decision-memo.aspx?NCAld=274.

17. de Koning HJ, van der Aalst CM, de Jong PA, Scholten ET, Nackaerts K, Heuvelmans MA, Lammers JJ, Weenink C, Yousaf-Khan U, Horeweg N, et al. Reduced lung-Cancer mortality with volume $C T$ screening in a randomized trial. N Engl J Med. 2020;382(6):503-13.

18. Mets OM, Buckens CF, Zanen P, Isgum I, van Ginneken B, Prokop M, Gietema HA, Lammers JW, Vliegenthart R, Oudkerk M, et al. Identification of chronic obstructive pulmonary disease in lung cancer screening computed tomographic scans. JAMA. 2011;306(16):1775-81.

19. Vogelmeier CF, Criner GJ, Martinez FJ, Anzueto A, Barnes PJ, Bourbeau J, Celli BR, Chen R, Decramer M, Fabbri LM, et al. Global Strategy for the Diagnosis, Management, and Prevention of Chronic Obstructive Lung Disease 2017 Report. GOLD executive summary. Am J Respir Crit Care Med. 2017;195(5):557-82.

20. Labonte LE, Tan WC, Li PZ, Mancino P, Aaron SD, Benedetti A, Chapman KR, Cowie R, JM FG, Hernandez P, et al. Undiagnosed chronic obstructive pulmonary disease contributes to the burden of health care use. Data from the CanCOLD study. Am J Respir Crit Care Med. 2016; 194(3):285-98.

21. Martinez $\mathrm{CH}$, Mannino DM, Jaimes FA, Curtis JL, Han MK, Hansel NN, Diaz AA. Undiagnosed obstructive lung disease in the United States. Associated factors and long-term mortality. Ann Am Thorac Soc. 2015; 12(12):1788-95.

22. Katki HA, Kovalchik SA, Berg CD, Cheung LC, Chaturvedi AK. Development and validation of risk models to select ever-smokers for CT lung Cancer screening. JAMA. 2016;315(21):2300-11.

23. Tammemagi MC, Katki HA, Hocking WG, Church TR, Caporaso N, Kvale PA, Chaturvedi AK, Silvestri GA, Riley TL, Commins J, et al. Selection criteria for lung-cancer screening. N Engl J Med. 2013;368(8):728-36.

24. Tammemagi MC, Schmidt H, Martel S, McWilliams A, Goffin JR, Johnston MR, Nicholas G, Tremblay A, Bhatia R, Liu G, et al. Participant selection for lung cancer screening by risk modelling (the pan-Canadian early detection of lung Cancer [PanCan] study): a single-arm, prospective study. Lancet Oncol. 2017;18(11):1523-31.

25. Tammemagi MC, Freedman MT, Pinsky PF, Oken MM, Hu P, Riley TL, Ragard $L R$, Berg CD, Prorok PC. Prediction of true positive lung cancers in individuals with abnormal suspicious chest radiographs: a prostate, lung, colorectal, and ovarian cancer screening trial study. J Thorac Oncol. 2009; 4(6):710-21.

26. Tremblay A, Taghizadeh N, McWilliams AM, MacEachern P, Stather DR, Soghrati K, Puksa S, Goffin JR, Yasufuku K, Amjadi K, et al. Low prevalence of high-grade lesions detected with autofluorescence bronchoscopy in the setting of lung Cancer screening in the pan-Canadian lung Cancer screening study. Chest. 2016;150(5):1015-22. 
27. Miller MR, Crapo R, Hankinson J, Brusasco V, Burgos F, Casaburi R, Coates A, Enright $P$, van der Grinten $C P$, Gustafsson P, et al. General considerations for lung function testing. Eur Respir J. 2005;26(1):153-61.

28. Bankier AA, De Maertelaer V, Keyzer C, Gevenois PA. Pulmonary emphysema: subjective visual grading versus objective quantification with macroscopic morphometry and thin-section CT densitometry. Radiology. 1999;211(3):851-8

29. Ostroff JS, Buckshee N, Mancuso CA, Yankelevitz DF, Henschke Cl. Smoking cessation following $C T$ screening for early detection of lung cancer. Prev Med. 2001;33(6):613-21.

30. Taghizadeh N, Taylor KL, MacEachern P, Koetzler R, Dickinson JA, Gillson A, Yang $\mathrm{H}$, Tammemagi MC, Penz E, Pendharkar SR, et al. Tobacco use and motivation to stop smoking among long-term smokers who are ineligible for lung cancer screening. Lung Cancer. 2017;111:101-7.

31. Cornuz J, Gilbert A, Pinget C, McDonald P, Slama K, Salto E, Paccaud F. Costeffectiveness of pharmacotherapies for nicotine dependence in primary care settings: a multinational comparison. Tob Control. 2006;15(3):152-9.

32. Tanner NT, Kanodra NM, Gebregziabher M, Payne E, Halbert CH, Warren GW Egede LE, Silvestri GA. The association between smoking abstinence and mortality in the National Lung Screening Trial. Am J Respir Crit Care Med. 2016;193(5):534-41.

33. Young RP, Hopkins RJ, Christmas T, Black PN, Metcalf P, Gamble GD. COPD prevalence is increased in lung cancer, independent of age, sex and smoking history. Eur Respir J. 2009;34(2):380-6.

34. Au DH, Udris EM, Fihn SD, McDonell MB, Curtis JR. Differences in health care utilization at the end of life among patients with chronic obstructive pulmonary disease and patients with lung cancer. Arch Intern Med. 2006; 166(3):326-31.

35. Goodridge D, Lawson J, Duggleby W, Marciniuk D, Rennie D, Stang M. Health care utilization of patients with chronic obstructive pulmonary disease and lung cancer in the last 12 months of life. Respir Med. 2008; 102(6):885-91.

36. Mittmann N, Kuramoto L, Seung SJ, Haddon JM, Bradley-Kennedy C, Fitzgerald JM. The cost of moderate and severe COPD exacerbations to the Canadian healthcare system. Respir Med. 2008;102(3):413-21.

37. Perera PN, Armstrong EP, Sherrill DL, Skrepnek GH. Acute exacerbations of COPD in the United States: inpatient burden and predictors of costs and mortality. Copd. 2012;9(2):131-41.

38. Briggs AH, Glick HA, Lozano-Ortega G, Spencer M, Calverley PM, Jones PW, Vestbo J, investigators TOaRiCH. Is treatment with ICS and LABA costeffective for COPD? Multinational economic analysis of the TORCH study. Eur Respir J. 2010;35(3):532-9.

39. Decramer M, Cooper CB. Treatment of COPD: the sooner the better? Thorax. 2010;65(9):837-41.

40. Sin DD, Golmohammadi K, Jacobs P. Cost-effectiveness of inhaled corticosteroids for chronic obstructive pulmonary disease according to disease severity. Am J Med. 2004;116(5):325-31.

41. Griffiths TL, Phillips CJ, Davies S, Burr ML, Campbell IA. Cost effectiveness of an outpatient multidisciplinary pulmonary rehabilitation programme. Thorax. 2001;56(10):779-84.

42. Young RP, Duan F, Chiles C, Hopkins RJ, Gamble GD, Greco EM, Gatsonis C, Aberle D. Airflow limitation and histology shift in the National Lung Screening Trial. The NLST-ACRIN cohort substudy. Am J Respir Crit Care Med. 2015;192(9):1060-7.

43. Fernandez-Villar A, Lopez-Campos JL, Represas Represas C, Marin Barrera L, Leiro Fernandez V, Lopez Ramirez C, Casamor R. Factors associated with inadequate diagnosis of COPD: on-Sint cohort analysis. Int J Chron Obstruct Pulmon Dis. 2015;10:961-7.

44. Regan EA, Lynch DA, Curran-Everett D, Curtis JL, Austin JH, Grenier PA, Kauczor HU, Bailey WC, DeMeo DL, Casaburi RH, et al. Clinical and radiologic disease in smokers with Normal Spirometry. JAMA Intern Med. 2015;175(9): 1539-49.

45. Woodruff PG, Barr RG, Bleecker E, Christenson SA, Couper D, Curtis JL, Gouskova NA, Hansel NN, Hoffman EA, Kanner RE, et al. Clinical significance of symptoms in smokers with preserved pulmonary function. N Engl J Med. 2016;374(19):1811-21.

46. Lutchmedial SM, Creed WG, Moore AJ, Walsh RR, Gentchos GE, Kaminsky DA. How common is airflow limitation in patients with emphysema on CT scan of the chest? Chest. 2015;148(1):176-84.

47. Omori $H$, Nakashima R, Otsuka N, Mishima $Y$, Tomiguchi S, Narimatsu A, Nonami Y, Mihara S, Koyama W, Marubayashi T, et al. Emphysema detected by lung cancer screening with low-dose spiral CT: prevalence, and correlation with smoking habits and pulmonary function in Japanese male subjects. Respirology. 2006;11(2):205-10.

48. Mohamed Hoesein FA, de Hoop B, Zanen P, Gietema H, Kruitwagen CL, van Ginneken B, Isgum I, Mol C, van Klaveren RJ, Dijkstra AE, et al. CT-quantified emphysema in male heavy smokers: association with lung function decline. Thorax. 2011;66(9):782-7.

49. Kim SS, Seo JB, Lee HY, Nevrekar DV, Forssen AV, Crapo JD, Schroeder JD, Lynch DA. Chronic obstructive pulmonary disease: lobe-based visual assessment of volumetric CT by using standard images--comparison with quantitative $C T$ and pulmonary function test in the COPDGene study. Radiology. 2013;266(2):626-35.

50. Hatayama O, Kobayashi T, Fujimoto K, Kubo K. Utility of single-slice highresolution $C T$ in upper lung field combined with low-dose spiral $C T$ for lung-cancer screening in the detection of emphysema. Intern Med. 2007; 46(18):1519-25.

\section{Publisher's Note}

Springer Nature remains neutral with regard to jurisdictional claims in published maps and institutional affiliations.
Ready to submit your research? Choose BMC and benefit from:

- fast, convenient online submission

- thorough peer review by experienced researchers in your field

- rapid publication on acceptance

- support for research data, including large and complex data types

- gold Open Access which fosters wider collaboration and increased citations

- maximum visibility for your research: over $100 \mathrm{M}$ website views per year

At BMC, research is always in progress.

Learn more biomedcentral.com/submissions 